\title{
PESQUISA E PROCESSOS FORMATIVOS DE EDUCADORES AMBIENTAIS NA RADICALIDADE DE UMA CRISE CIVILIZATÓRIA
}

\author{
Mauro Guimarães ${ }^{1}$
}

\begin{abstract}
Resumo
Vivemos graves problemas socioambientais, na atualidade, que alcançaram a escala global, colocando em risco a vida planetária. Esses problemas são indicadores de uma crise civilizatória pelo colapso do modo de organização social, civilização capitalista industrial moderna, na sua relação de dominação e exploração da Natureza, consequente do paradigma da disjunção e simplificação da modernidade. A grave e urgente situação de crise, que ruma para um abismo, remete a pensarmos na radicalidade da formação de educadores ambientais que possam ser dinamizadores de movimentos de enfrentamento dessa realidade. Para isso, apresentamos a proposta teórico-metodológica da ComVivência Pedagógica para a formação de emuladores ambientais, que o coletivo de pesquisadores reunidos no GEPEADS/UFRRJ está desenvolvendo.
\end{abstract}

Palavras-chave: Crise civilizatória. Educação Ambiental. Formação de Educadores.

\section{RESEARCH AND TRAINING PROCESSES OF ENVIRONMENTAL EDUCATORS IN THE RADICALITY OF A CIVILIZATIONAL CRISIS}

\begin{abstract}
We live serious socio-environmental problems, nowadays, that have reached the global scale, putting at risk planetary life. These problems are indicative of a civilizational crisis by the collapse of the mode of social organization, modern industrial capitalist civilization, in its relation of domination and exploration of Nature, consequent of the paradigm of the disjunction and simplification of modernity. The serious and urgent situation of crisis, which leads to an abyss, leads us to think of the radical formation of environmental educators that can be the driving force of the movement to confront this reality. For that, we present the theoretical-methodological proposal of the Pedagogical ComVivencia for the formation of environmental educators, that the collective of researchers gathered in GEPEADS / UFRRJ is developing.
\end{abstract}

Keywords: Civilization crisis. Environmental education. Educators formation.

\section{INVESTIGACIÓN Y PROCESOS FORMATIVOS DE EDUCADORES AMBIENTALES EN LA RADICALIDAD DE UNA CRISIS CIVILIZATORIA}

\section{Resumen}

Vivimos graves problemas socioambientalesenlaactualidad, que alcanzaronla escala global, poniendoenriesgola vida planetaria. Estos problemas son indicadores de una crisiscivilizatoria por el colapso del modo de organización social, civilización capitalista industrial moderna, ensurelación de dominación y explotación de la Naturaleza, consecuentedel paradigma de ladisyunción y simplificación de lamodernidad. La grave y urgente situación de crisis, que se

\footnotetext{
${ }^{1}$ Professor Pesquisador do Programa de Pós-Graduação em Educação (PPGEduc) da Universidade Federal Rural do Rio de Janeiro. Pós Doutor e Mestre em Educação; Doutor em Ciências Sociais, Especialista em Ciências Ambientais e Graduado em Geografia.guimamauro@hotmail.com
} 
dirige haciaun abismo, remite a pensar enlaradicalidad de laformación de educadores ambientales que puedan ser dinamizadores de movimientos de enfrentamiento de esta realidad. Para ello, presentamos lapropuesta teórico-metodológica de la ComVivencia pedagógica para laformación de educadores ambientales, que elcolectivo de investigadores reunidos en el GEPEADS / UFRRJ está desarrollando.

Palabras claves: Crisiscivilizatoria. Educación ambiental. Formación de Educadores.

\section{1- A crise como pressupostos}

Inicio este artigo, fazendo coro com Michel Löwy ${ }^{2}$ (2017, s/p) quando denuncia o caminho do ecossuicídio que nossa civilização está trilhando:

A civilização capitalista industrial moderna é um trem suicida que avança, com rapidez crescente, em direção a um abismo: as mudanças climáticas, o aquecimento global. Trata-se de um processo dramático que já começou, ... A partir de um certo nível de temperatura, será ainda possível a vida humana neste planeta?

Acreditar que podemos, cada vez mais, extrair recursos naturais, para transformar em mercadorias, muitas destas desnecessárias e supérfluas, para garantir uma economia que não pode parar de crescer, e tudo isso em um planeta finito e limitado em seus recursos, parece que é querer baixar os olhos para não ver o abismo que se aproxima!

Nossos alimentos animais, por exemplo, são criados como mercadorias, vivendo como objetos encarcerados, sem a mínima preocupação com suas qualidades de vida, em ambientes insalubres, controlados por uma química medicamentosa intoxicante, voltados exclusivamente para o aumento da produtividade e gananciosos lucros.

Acreditar que a qualidade de vida desses outros seres não nos afeta, como se estivéssemos isolados de tudo isso, consiste em nos iludirmos, julgando que somos independentes das relações vitais que compõe a Natureza. Parece que é olhar e não querer ver que a degradação da Natureza nos contamina, nos destrói e desumaniza.

Acreditar que é com mais desenvolvimento econômico e progresso tecnológico que resolveremos os grandes problemas socioambientais que afligem a grande maioria dos seres viventes, hoje, no planeta, demonstra que há algo incoerente na forma de pensar desse modelo civilizatório que se globalizou. Pois esses problemas se intensificaram e se agravaram, justamente, no período histórico atual, em que esse modo de organização social mais gerou riqueza e atingiu o nível de desenvolvimento tecnológico jamais visto. Parece que essa incoerência é baixar os olhos para não ver o veneno dado ao enfermo envenenado!

Acreditar que ser vitorioso socialmente é adquirir riqueza e poder, isso implica em estar míope para a degradação ética, social, ecológica causada pelo padrão relacional de dominação e exploração, prevalente na modernidade, que enriquece e empodera uns poucos, às custas da exploração e degradação de tantos outros, seres humanos-natureza.

Vivemos pelos paradigmas da modernidade ${ }^{3}$, que nos disjuntam e hierarquizam as relações (uns que são mais e muitos outros que são menos), a crença de que somos, como espécie, os seres superiores e, por isso, subjugamos, dominamos e pré-determinamos a todos os outros seres animados e inanimados que se conjugam como Natureza, aos nossos únicos e exclusivos interesses particulares (a parte superior aos outros). Noção que vem distanciando, cada vez mais, sociedade humana da Natureza, criando uma percepção de não pertencimento, como se fôssemos senhores da Natureza - Dessa mesma forma, se reproduz nas relações

\footnotetext{
${ }^{2}$ Entrevista concedida a Miguel Fuentes em 10/05/2017, publicado em: <https//outraspalavras.net/posts/lowyhistoria-razoes-e-etica-do-ecossocialismo>.

${ }^{3}$ Edgar Morin (1999), em sua obra sobre a complexidade, denomina de paradigma da disjunção e simplificação a estrutura de pensamento que referencia toda a visão de mundo da modernidade e sua racionalidade.
} 
sociais uma elite de senhores que não se reconhecem e se identificam com os subalternos da sociedade, humanos que todos somos.

Tudo isso disjunta, simplificando e reduzindo a compreensão de uma realidade socioambiental complexa, que vai se constituindo em uma grave crise que ameaça a vida de todos nós, Natureza que somos também!

Essas referências paradigmáticas são estruturantes do nosso modo de organização social que, hegemonicamente, dominou e se globalizou, atingindo uma escala planetária. Vivemos, hoje, essa grave crise que é mundial!

\section{2 - Modelo civilizatório em degradação}

Esse modelo civilizatório (capitalista, industrial, moderno) que é como "um trem suicida que avança, com rapidez crescente, em direção a um abismo" (LÖWY, 2017, s/p), hipertrofia a presença humana na vida. Essa postura diante da vida/Natureza representa o desequilíbrio gerado, quando uma parte,numa dimensão hipertrofiada, se sobrepõe às demais, na ilusão de que, como dominador, superior, se coloca como o Todo Poderoso, porém, exerce um poder degradante e destrutivo das relações de equilíbrio ecológico, assim como, de equilíbrio social.

No equilíbrio do Bem Viver $^{4}$ as partes são conectadas e interdependentes, no entanto, o ser social moderno, em nossa arrogante crença de dominação, jamais se coloca como dependente de outro, antes, apresenta-se como senhor! Visão que produz a cegueira de um conhecimento que, em sua racionalidade instrumental ${ }^{5}$, constrói a crença de um caminho único, cheio de certezas, que pré-determina um modelo de vida para todos e proclama o Fim da História ${ }^{6}$.

Conhecimento resultante de uma tradição Iluminista, que engendrou uma ciência moderna, no âmbito da qual a razão sobrepuja a emoção, em uma pretensa neutralidade que busca, numa objetividade, sobrepor a subjetividade de forma positiva, para ditar verdades como certezas e afastar o medo das incertezas. Que, na separação das coisas, disjunta matéria e espírito, superlativando o materialismo consumista do individualismo, de uma percepção espiritualizada da vida coletiva, em comunidade. Que, no extremo, nos coloca isolados em nós mesmos, construindo grades para nos isolar e manter o senso de controle, como nos condomínios de luxo como ilhas em meio a um mar de miséria dos nossos grandes centros urbanos.

Essas presunções e posturas dominadoras, excludentes, individualistas, particularistas, economicistas e cientificistas dessa visão social de mundo que se planetarizou, tem um forte indicador de colapso desse modelo civilizatório. Colapso quando este modo de ser e estar de dominação e exploração da sociedade humana diante da Natureza provoca os problemas ambientais numa escala planetária, como aquecimento global, mudanças climáticas, extinção em massa de espécies, contaminação das águas, entre muitos outros, que, infelizmente, ameaçam a vida como um todo na Terra.

Assim como esse modo de ser e estar de dominação e exploração de uma elite social sobre os demais, que numa escala globalizada, produz cada vez maior concentração de

\footnotetext{
${ }^{4}$ O Bem Viver constitui-se em um princípio da cosmovisão do conhecimento ancestral andino. Refere-se a saber viver em harmonia com os ciclos da Madre Tierra, compreendendo que a deterioração de uma espécie é a deterioração do conjunto.

${ }^{5}$ Refere-se, em última instância, à dominação da natureza para fins lucrativos pelo Capitalismo, colocando a ciência e a técnica a serviço do capital. Teóricos da Escola de Frankfurt, principalmente Horkheimer, identificam a origem da irracionalidade do sistema na razão instrumental.

${ }^{6}$ É a tese defendida por Francis Fukuyama (1992), logo após a queda do muro de Berlim, propondo que com o capitalismo e a democracia burguesa, a humanidade teria atingido o ponto culminante de sua evolução.
} 
riqueza, promovendo uma desigualdade excludente em todo o mundo. Desigualdade que gera a violência social crescente das drogas, das armas, da segregação social e espacial das cidades, da migração desesperada dos desvalidos pela fome e guerras no mundo. E a reação a toda essa crise, pela mesma forma de pensar disjuntiva e excludente, se dá no recrudescimento do Fascismo, no desvelamento do racismo, nas radicalizações sectárias político-religiosas e outras manifestações que apontam para a barbárie.

Um retrato espacializado desse processo de degradação da vida, da natureza, é o processo crescente de urbanização desse modo de vida da modernidade e que vem gerando o que estou, aqui, chamando de Escala Desumana de Vida.

Grandes centros urbanos são o lócus da modernidade. A manifestação espacial desse processo de acumulação crescente e ilimitada de capital que, ao se concentrar, gera um fluxo da dinâmica desse modo de vida para o espaço urbano.

O moderno está nas cidades. Na roça, nas aldeias indígenas, onde a Natureza está mais presente de forma não dominada/transformada, consideramos primitivo. $\mathrm{O}$ crescimento urbano tornou-se inerente a essa forma de desenvolvimento da modernidade; símbolo do progresso desse modo de vida. As cidades pequenas caminhando para médias, as médias para grandes, rumando para metrópoles globais. Esse é o caminho único prescrito e de desejo produzido e inquestionável de progresso, o qual seguimos e desejamos sem questionar.

Nesses centros urbanos que se agigantam, adensam populações vivendo cada vez mais dessa forma disjuntiva, individualistas e materialistas em um consumo desenfreado e ensimesmado. Isso para suprir um senso de realização com externalidades superficiais e alienantes, para preencher um vazio existencial da falta de realizações interiores, algo que é da essência do processo de humanização e que se realiza por meio de relações harmoniosas da amorosidade $^{7}$ com o outro - indivíduo, comunidade, Natureza.

É nesta direção que se intensificam, como um dos maiores e crescentes males da modernidade, a depressão, a falta de sentido para a vida, a sensação de solidão em meio às multidões, a síndrome de pânico. Sentimentos presentes em um modo de vida disjuntivo em que as relações se diluem e escorrem para o mundo virtual de uma modernidade líquida ${ }^{8}$ (BAUMAN, 2001).

A esses sentimentos que falseiam o sentido de realização da vida, que na dimensão hipertrofiada da modernidade manifestam-se profundamente nos centros urbanos, junta-se uma série de outras repercussões degradantes e em desequilíbrio deste modo de vida nas relações entre os próprios humanos e destes em sociedade com a Natureza. A essa dimensão hipertrofiada das ações e consequências da presença humana na vida do planeta é que estou, aqui, chamando de Escala Desumana de Vida.

A Escala Desumana de Vida manifesta-se, exponencialmente, nesses espaços urbanos quando, resultado do consumismo desse modo de vida disjuntivo, a concentração energética e de recursos são supridas pela drenagem exploratória e degradante, de um fluxo que se importa de outros espaços não urbanos e que, hoje, se avizinha aos limites planetários.

A isso Marx, segundo Foster (2005), já denunciava como a falha metabólica ${ }^{9}$ do modo de produção capitalista na relação dilapidante da sociedade para com a Natureza. Esse modo de organização social possui uma pegada ecológica ${ }^{10}$ de um megaimpacto muito acima de

\footnotetext{
${ }^{7}$ Como nos apresentou Paulo Freire (1987), que é no processo de humanização, no reconhecimento da incompletude do humano, a busca do Ser Mais nas relações dialógicas de amorosidade com o outro, com o mundo.

${ }^{8}$ Para Zygmunt Bauman (2001), na sociedade contemporânea, emergem o individualismo, a fluidez e a efemeridade das relações. Para ele, vivemos tempos líquidos em que nada foi feito para durar.

${ }^{9}$ Para maior entendimento, ver A Ecologia de Marx: materialismo e natureza, de John Bellamy Foster.

${ }^{10}$ Expressão usada para referenciar a contabilidade ambiental que avalia a pressão do consumo das populações humanas sobre os recursos naturais.
} 
qualquer outro ser vivente no mundo. Assim como também nos distanciou, de tal forma, de uma escala humana de vida, em que a reprodução individual e coletiva era garantida em uma intervenção mais local e em menor escala, como já, na década de 70 do século XX, E.F. Schumacher (1979) apresentava em sua interessante obra "O negócio é ser pequeno".

Essa Escala Desumana também está presente quando nesses espaços urbanos o processo de degradação socioambiental se concentra e se intensifica. Para vivermos essa modernidade concentrada nos centros urbanos, ao mesmo tempo vivenciamos ambientes poluídos, degradados socioambientalmente em moradias precárias; lixo crescente e contaminação das águas; transportes incapazes de dar conta da concentração populacional e suas necessidades de deslocamento, que consomem grande parte do tempo da vida das pessoas; conviver com a crescente violência social e tantas outras mazelas da contemporaneidade.

Vivemos essa Escala Desumana de Vida como rãs colocadas na água (que lhes dá vida) de uma panela em aquecimento e que não percebem, morrem, então,cozidas naquela água fervente. Aceitarmos que as coisas sempre foram assim, é estarmos sentados passivamente no "trem suicida que avança, com rapidez crescente, em direção a um abismo" (LÖWY, 2017, s/p), acreditando que há somente um único caminho a seguir: o dos trilhos do trem da modernidade.

\section{3 - A transformação da realidade.}

É nesse ponto que acredito que a Educação Ambiental Crítica ${ }^{11}$ pode contribuir, para que enfrentando a crise de um abismo que se faz imediato, possamos atuar para mudar o rumo do trem em que todos nós estamos embarcados.

Para isso, uma questão que venho me debatendo para ser superada é como fazer com que os educadores ambientais possam, de fato, contribuir com a transformação significativa da grave realidade que se apresenta? Principalmente, quando percebi em minha pesquisa de doutoramento que nós, educadores, mesmo que bem-intencionados em contribuir com o enfrentamento dos problemas ambientais, pouco efetivos estávamos sendo.

Vide que hoje tanto se faz Educação Ambiental (EA), muito mais que no passado, no entanto a sociedade, hoje, degrada muito mais a Natureza. Foi desde essa pesquisa que venho discutindo a armadilha paradigmática ${ }^{12}$ a que estamos sujeitos e que nos faz, em nossas ações, reproduzirmos inconscientemente os paradigmas disjuntivos da modernidade; justamente paradigmas que gestam os grandes problemas socioambientais e a crise civilizatória da atualidade, como desenvolvo em Guimarães (2006).

É muito forte a influência do paradigma disjuntivo na construção de uma razão instrumental que nos leva a acreditar no caminho único (a linha do trem) proposto pelo atual modo de vida hegemônico da civilização capitalista industrial moderna.

Morin (1997, p.21) nos diz que o Paradigma é a "estrutura de pensamento que de modo inconsciente comanda o nosso discurso". Essa inconsciência dessa estrutura de

\footnotetext{
${ }^{11}$ Acreditamos que a perspectiva crítica da Educação Ambiental é a que questiona e problematiza, em sua práxis pedagógica, a civilização capitalista industrial moderna em suas relações de poder, estruturantes de seu modo de produção e consumo, que resulta como inerentes a esse modo de organização social as desigualdades sociais e a degradação da Natureza. Dessa feita, propõe formar cidadãos para atuar no processo de transformação da atual realidade rumo a um outro modelo de sociedade, que seja socioambientalmente sustentável.

${ }^{12}$ Inicio esta discussão no livro "A formação de educadores ambientais", de 2004, quando "professores foram ou estão sendo formados, em sua maioria, na mesma perspectiva conservadora de educação que reproduz $a$ e se reproduz na armadilha paradigmática. Ou seja, dada uma compreensão de mundo moldada pela racionalidade hegemônica, geram-se práticas, entre elas a ação discursiva, incapazes de fazer diferente do "caminho único" prescrito por essa racionalidade, efetivando-se a hegemonia" (GUIMARÃES, 2004, p.124).
} 
pensamento disjuntiva, que separa, hierarquiza uma parte da outra e estabelece uma relação de dominação e exploração do mais forte sobre os vulneráveis, está tão impregnada em nosso dia a dia, que nem mais a percebemos informando o nosso discurso e ações. Fazemos deste jeito porque sempre foi assim; isso é tão normal, que nem mais pensamos nisso, fazemos; isso representa um agir no automático, em que essa ação está, inconscientemente, impregnada de referências disjuntivas. Essa é uma importante influência do paradigma em nossa vida cotidiana: disjuntamos a reflexão da ação; deixamos de questionar o mundo como ele é e o aceitamos, passivamente, sentados no banco do trem rumo ao abismo, sem nem percebermos que o trem está em movimento!

Como fazer para tirar o educador dessa inconsciência e desse agir no automático em suas ações educativas, para que este possa, de fato, ser um sujeito dentro do trem, consciente que está em movimento em direção ao abismo e que outro rumo é fundamental para salvar a todos dentro do trem?

Foi com essas questões: como enfrentar a radicalidade da crise civilizatória que vivemos; como fazer com que os educadores ambientais possam, de fato, contribuir com a transformação significativa da grave realidade que se apresenta; como fazer para tirar o educador dessa inconsciência e desse agir no automático em suas ações educativas, que, em 2013 , iniciamos um projeto de pesquisa ${ }^{13}$ que buscou investigar o processo formativo do educador ambiental e que procuro enunciar, aqui, alguns dos passos dados.

A motivação para esse projeto se deu por uma experiência pessoal que considerei muito significativa, quando, em 2012, fui com outros professores e alunos da graduação de Geografia da UFRRJ, a um trabalho de campo em que ficamos uma semana convivendo em uma aldeia indígena Krahô (Pedra Branca), no interior de Tocantins. Foi uma semana de uma convivência muita intensa vivida a partir do cotidiano do modo de vida Krahô.

Ao retornar para a Universidade percebi o quanto aquela experiência foi transformadora para mim. Até então, sempre fui intelectualmente simpático à causa indígena, mas a partir de então a questão indígena ganhou uma nova dimensão em minha vida, tornando-se uma questão fundamental no meu viver. Era algo que racionalizava como importante, mas, agora, também sentia como parte de minha vida, me aproximando de forma mais integral dessa realidade.

\section{4 - A radicalidade do processo formativo.}

Então, partindo disso e entendendo a urgência e a necessidade da radicalidade do momento histórico, nessa pesquisa juntamos um grupo de educadores ambientais em formação, com professores e alunos de pós-graduação e graduação. Procuramos, ao longo de um processo formativo de dois anos, propiciar ambientes educativos em que as armadilhas paradigmáticas pudessem ser desarmadas, para que os educadores se percebessem sujeitos dentro do trem. Uma forma que experimentamos como processo formativo, foi provocar a ruptura com o modo de vida da modernidade a partir desse choque de realidade na convivência intensa, imersa em um outro modo de vida, baseado em referências totalmente diversas da modernidade, na busca radical do reencontro com o natural ${ }^{14}$.

\footnotetext{
13 “Outras epistemologias no processo formativo de educação ambiental”, financiado pelo CNPq 2014-2015, foi um projeto Interinstitucional que contou com a participação de três grupos de Pesquisa: Grupo de Estudos e Pesquisa em Educação Ambiental, Diversidade e Sustentabilidade (GEPEADS/UFRRJ), coordenado por mim; Grupo de Educação Ambiental desde elSur (GEASur/UNIRIO), coordenado pelo Prof. Dr. Celso Sanchez; Grupo de Estudos dos Povos Tradicionais (GEOPOVOS/UFRRJ), coordenado pelo Prof. Dr. Emerson Guerra.

14 “'O 'reencontro com o natural' oportuniza ao educador ambiental em formação a experiência de reconexão nos universos interno e externo, contextualizadas em cotidianos onde a natureza permeia, objetiva e subjetivamente, integralmente, as relações. Nessas vivências, ele tem a oportunidade de perceber a dimensão complexa da
} 
O "reencontro com o natural" é a possibilidade de restituição ao ser humano do seu ambiente vital, de sua capacidade ancestral de sentir-se em comunhão com o todo, e com isso, naturalmente "ouvir" a natureza; de se reencantar pela força conectiva da amorosidade com outros seres e elementos com quem coabitamos no planeta; de sacralização da vida (incluindo a morte) como um bem maior. É uma proposta otimista, que evoca uma libertação, tanto para si como para a Terra, das ameaças representadas pelos incessantes equívocos e descontrolada ganância, que vêm caracterizando as atividades humanas no planeta, priorizando os interesses econômicos acima de tudo (GUIMARÃES; GARNIER, 2017, p.14).

Essa imersão vivencial em uma realidade de vida totalmente diferenciada da nossa experiência como seres da modernidade, se deu com etapas preparatórias. Nessas etapas buscamos conhecer, cognitivamente, a cultura e história do povo Krahô (Tocantins), Guarani (Rio de Janeiro) e Quechua (Bolívia), com quem pudemos, numa perspectiva intercultural ${ }^{15}$, estabelecer um processo de convivência que se mostrou extremamente pedagógica para o processo formativo desses educadores. A esse processo formativo estamos chamando de ComVivência Pedagógica ${ }^{16}$.

Estamos, como pesquisadores coletivos integrantes do GEPEADS, procurando investigar essa ComVivência Pedagógica como uma proposta teórico-metodológica de processo formativo de educadores ambientais, na radicalidade de tempos de crise civilizatória. Estamos investigando ambientes educativos de ComVivência Pedagógica em diferentes experiências de convívio de outros modos de vida, baseados em referências diversas da modernidade, como: comunidades alternativas; comunidade do Santo Daime; movimento de produtores de agricultura orgânica; comunidade Quilombola; experiências vivenciais como o Caminho de Santiago-Espanha.

Nesse ínterim, já produzimos publicações ${ }^{17}$, quatro dissertações ${ }^{18}$, pesquisa de pósdoutoramento e estamos com teses de doutorado e dissertações de mestrado em andamento. Acreditamos, com isso, contribuir na formulação de uma epistemologia da Complexidade Ambiental (LEFF, 2003), fundamental para a construção do saber ambiental (LEFF, 2008) necessário à mudança dos rumos da caminhada da humanidade.

[...] sustentada por valores (qualidade de vida, identidades culturais, sentidos da existência) que não aspiram alcançar um estatuto de cientificidade. Abre-se aqui um diálogo entre ciência e saber, entre tradição e modernidade. Este encontro de saberes implica processos de hibridação cultural (GARCIA CANCLINI, 1990), onde se revalorizam os conhecimentos indígenas e os saberes populares produzidos por

dependência, em relações antagônicas, concorrentes e complementares, que o ser humano tem com a natureza. O sentido do cuidar, a importância de respeitar e a necessidade de se conectar, para melhor compreender e viver a natureza em equilíbrio com ela e, consequentemente, consiglo mesmo" (GUIMARÃES; GARNIER, 2017, p.13.)

15 “A interculturalidade é a interação entre culturas num processo de comunicação entre diferentes grupos humanos, com diferentes costumes, sendo a característica fundamental a horizontalidade (na mesma perspectiva dialógica Freireana). Nenhum grupo está acima de outro, promove-se a igualdade, a integração e a convivência harmônica entre elas" (CAVALIÉ APAC, 2013, p.03). Disponível em: https://www.servindi.org/actualidad/80784. Acessado em 14/02/2018. Grifo do autor. Para maior esclarecimento, ver Walsh (2009).

${ }^{16}$ A ComVivência Pedagógica é uma proposta teórico-metodológica, adotada no presente processo formativo, pela qual o ambiente educativo se constrói em uma práxis pedagógica de educadores ambientais em formação, na convivência com outros grupos humanos silenciados na modernidade. Propõe-se, pela radicalidade de experiências vivenciais de outros referenciais epistemológicos, o exercício da dialogicidade de novas relações conectivas com o outro, com o mundo (GUIMARÃES; GARNIER, 2017.)

${ }^{17}$ Guimarães \& Prado (2014); Guimarães \&Medeiros (2016); Guimarães \& Pinto (2017); Guimarães \&Garnier (2017).

${ }^{18}$ Dissertações defendidas decorrentes desse esforço coletivo de pesquisa: Ferreira (2016); Gonçalves (2017); Garnier (2017); Santos (2018). 
diferentes culturas em sua coevolução com a natureza, e onde estes se amalgamam com formações discursivas, teorias científicas [...]. O saber ambiental levanta a questão da diversidade cultural no conhecimento da realidade, mas também o problema da apropriação de conhecimentos e saberes dentro de diferentes ordens culturais e identidades étnicas (LEFF, 2008. p. 231).

Estamos nesse esforço coletivo de pesquisa $^{19}$, identificando e descrevendo alguns princípios formativos que acreditamos importantes de serem vivenciados nesses ambientes educativos; tais sejam até o momento: desestabilização criativa; indignação ética; reflexão crítica; postura conectiva; intencionalidade transformadora; sentimento de pertencimento pela amorosidade.

O que acreditamos é que o educador no processo formativo, passando por experiências vivenciais profundas de ruptura com o modo de vida da modernidade possa, como sujeito no trem, transformado e transformador, assumir em sua práxis o compromisso com outros modos de vidas possíveis. Que seja um interventor no cotidiano, na construção de novas relações diversas dos padrões da modernidade, para que como educador, cidadão, ator social, exerça o papel de dinamizador de movimentos emergentes ${ }^{20}$ contra hegemônicos. Movimentos potencializadores das reformas de pensamento e o processo de transição paradigmática (Santos, 2000). Transição que se mostra urgente e necessária, de um modo de vida que, em crise civilizatória, está com suas certezas sendo colocadas diante do abismo.

\section{Bibliografia}

BAUMAN, Z. Modernidade Líquida. Rio de Janeiro: Jorge Zahar Editora, 2001.

CAVALIÉ APAC, 2013. Disponível em: https://www.servindi.org/actualidad/80784. Acessado em 14/02/2018.

FERREIRA, H.S. O processo de ensino aprendizagem em outras epistemologias na formação do educador ambiental. 2016. Dissertação (Mestrado em Educação) - Universidade Federal Rural do Rio de Janeiro, Seropédica, 2016.

FOSTER, J.B.A Ecologia de Marx: materialismo e natureza.Rio de Janeiro: Civilização Brasileira, 2005.

FREIRE, P. Pedagogia da Esperança. Rio de Janeiro: Paz e Terra, 1992.

Pedagogia do Oprimido. 17ª ed. Rio de Janeiro: Paz e Terra, 1987.

GONÇALVES, E.J. Educação Ambiental e outras epistemologias na formação do educador.2017. Dissertação (Mestrado em Educação) - Universidade Federal Rural do Rio de Janeiro, Seropédica, 2017.

GARNIER, N.B. Experiências de "ComVivência Pedagógica" a partir de outras epistemologias em processos formativos de educadores ambientais. 2017. 168 f. Dissertação (Mestrado em Educação) Universidade Federal Rural do Rio de Janeiro, Seropédica, 2017.

GUIMARÃES, M. A formação de educadores ambientais. Campinas, Papirus, 2004.

\footnotetext{
${ }^{20}$ Para maior esclarecimento, ver Boaventura de Souza Santos - Para uma Sociologia das Ausências e uma Sociologia das Emergências (2002).
} 
GUIMARÃES, M. Outras epistemologias no processo formativo de Educação Ambiental. CNPq, (Projeto). Brasília: Edital Universal, 2013.

GUIMARÃES, M.; GARNIER, N. B. Educação ambiental e os processos formativos em tempos de crise. Revista Diálogo Educacional,Curitiba,v. 17, n. 55, p. 1574-1597, Dez. 2017.

. Armadilha paradigmática na educação ambiental. In: LOUREIRO, C. F. B.; LAYRARGUES, P. P. L.; CASTRO, R. S. de. (Orgs.). Pensamento complexo, dialética e educação ambiental. São Paulo: Cortez, 2006.

GUIMARÃES, M.; PINTO, V. P. S. Alternativas para processos formativos de educação ambiental: a proposta da "(com)vivência pedagógica" diante de grandes e radicais desafios. Revista Eletrônica do Mestrado em Educação Ambiental. Rio Grande, Edição especial XVI Encontro Paranaense de Educação Ambiental, p. 118-131, 2017.

GUIMARÃES, M. e MEDEIROS, H. Outras epistemologias em educação ambiental: o que aprender com os saberes tradicionais dos povos indígenas. Rev. Eletrônica Mestrado em Educação Ambiental. Ed. Especial, julho/2016.

GUIMARÃES, M.; PRADO, C. Educação em Direitos Humanos e Educação Ambiental: Ética e História. In: SILVA, A. M. M.; TIRIBA, L. (orgs.). Direito ao ambiente como direito à vida: desafios para a educação em direitos humanos. Coleção educação em direitos humanos. 1 ed. São Paulo: Cortez, 2014.

LEFF, E. A Complexidade Ambiental. São Paulo: Cortez, 2003.

LEFF, E. Saber Ambiental. Petrópolis: Vozes, 2008.

LÖWY, M. Entrevista concedida a Miguel Fuentes em 10/05/2017. Disponível em: https//outraspalavras.net/posts/lowy-historia-razoes-e-etica-do-ecossocialismo. Acesso: 14/02/2018.

MORIN, E. Complexidade e ética da solidariedade. In: CASTRO, G. de; CARVALHO, E. de A.; ALMEIDA, M. C. de (Coords.). Ensaios de Complexidade. Porto Alegre: Sulina, 1997. p.15-24.

MORIN, E. Ciência com Consciência. 3 ed. Rio de Janeiro: Bertrand Brasil, 1999.

SANTOS B. de S. A crítica da razão indolente: contra o desperdício da Experiência. São Paulo: Cortez, 2000.

SANTOS B. de S. Para uma Sociologia das Ausências e uma Sociologia das Emergências.Revista Crítica de Ciências Sociais, Coimbra,n. 63, p. 237-280. Out.2002.

SANTOS, D. G. G. dos. A relação entre sentimento de pertencimento e a educação ambiental. 2018. Dissertação (Mestrado em Educação) - Universidade Federal Rural do Rio de Janeiro, Seropédica, 2018.

SCHUMACHER, E. F. O negócio é ser pequeno. Rio de Janeiro: Editora Zahar, 1979.

WALSH, C. Educação Intercultural na América Latina: entre concepções, tensões e propostas. In: CANDAU, V. (Org). Interculturalidade Crítica e Pedagogia Decolonial: in-surgir, re-existir e reviver. 2009. p. 12-42. Disponívelem:<https://pt.scribd.com/document/132966867/WALSH-Catherineinterculturalidade-critica-e-pedagogia-decolonial>. Acesso em: 25 jul. 2017. 